\title{
One year measurements of aerosol optical properties over an urban coastal site: Effect on local direct radiative forcing
}

\author{
Auromeet Saha ${ }^{\mathrm{a}, *}$, Marc Mallet ${ }^{\mathrm{b}}$, Jean Claude $\operatorname{Roger}^{\mathrm{c}}$, Philippe Dubuisson ${ }^{\mathrm{d}}$, \\ Jacques Piazzola ${ }^{a}$, Serge Despiau ${ }^{a}$ \\ a LSEET-LEPI, UMR 6017, Université du Sud Toulon-Var, La Garde, France \\ ${ }^{\mathrm{b}}$ Laboratoire d'Aerologie, Université Paul Sabatier, Toulouse, France \\ c Laboratoire de Météorologie Physique, Université Blaise Pascal, Aubière, France \\ d Écosystèmes Littoraux et Côtiers, Université du Littoral, Wimereux, France
}

\begin{abstract}
We present results of direct aerosol radiative forcing over a French Mediterranean coastal zone based on one year of continuous observations of aerosol optical properties during 2005-2006. Monthly-mean aerosol optical depth at $440 \mathrm{~nm}$ ranged between 0.1 and 0.34 , with high Angstrom coefficient ( $\alpha>1.2$ ). The single scattering albedo (at $525 \mathrm{~nm}$ ) estimated at the surface ranged between 0.7 and 0.8 , indicating significant absorption. The presence of aerosols over the Mediterranean zone during summer decreases the shortwave radiation reaching the surface by as much as $26 \pm 3.9 \mathrm{~W} \mathrm{~m}^{-2}$, and increases the top of the atmosphere reflected radiation by as much as $5.2 \pm 1.0 \mathrm{~W} \mathrm{~m}^{-2}$. The shortwave atmospheric absorption translates to an atmospheric heating of 2.5 to $4.6 \mathrm{~K} \mathrm{day}^{-1}$. Concerted efforts are needed for investigating the possible impact of the increase in heating rate on the maintenance of heat-waves frequently occurring over this coastal region during summer time.
\end{abstract}

\section{Introduction}

The radiative forcing due to aerosols is poorly characterized in climate models because of the lack of comprehensive database on aerosol optical properties. To fill this gap, numerous field experiments have been undertaken in the recent years. Some of the recent field experiments include Aerosol Characterization Experiments (ACE-1 and ACE-2), Smoke, Clouds, Aerosols, Radiation-Brazil (SCAR-B), Tropospheric Aerosol Radiative Forcing Observational Experiment (TARFOX), Indian Ocean Experiment (INDOEX), Experience sur Site pour COntraindre les Modeles de Pollution atmospherique et de Transport d'Emissions (ESCOMPTE), and Mediterranean Intensive Oxidant Study (MINOS). However,

\footnotetext{
* Corresponding author. Department of Atmospheric Sciences, Texas A\&M University, College Station, TX 77843-3150, USA. Tel.: +1 979458 0177; fax: +1 9798624466.

E-mail addresses: auromeet@ariel.met.tamu.edu, auromeet@gmail.com (A. Saha).
}

many of these field experiments were conducted over the oceans, and the characterization of aerosols and their radiative effects over urban and coastal environments has been very limited. ESCOMPTE was conducted in southeastern part of France, including the urban area of the city of Marseille and the large industrial complex of Fos-Berre (Cros et al., 2004), and MINOS was conducted in the Greek island of Crete in Summer 2001 (Lelieveld et al., 2002). ESCOMPTE was a field campaign devoted to establish a detailed database of primary pollutant emissions together with dynamics and chemistry of the atmosphere during high pollution events. MINOS was a comprehensive field experiment to investigate anthropogenic contributions to the environment of the eastern and central Mediterranean, and provided measurements of the aerosol chemistry, microphysics, and radiation. Even though field experiments provide very good snapshot information of aerosol radiative properties, the temporal coverage is not so good, since the experiments are limited to a short duration of time, spanning from few days to over a month. 
The main objective of this study is to present the results based on continuous measurements of optical properties of aerosols over urban coastal zone for one complete year and to estimate the local radiative effects based on these observations. Clear-sky conditions prevailed over this Mediterranean coast during most of the year, thereby providing an excellent setting for studying the radiative effects of anthropogenic and natural aerosols over this region.

\section{Experimental setup and instrumentation}

The instruments used in this study are installed in the Toulon University campus in La Valette $\left(43.14^{\circ} \mathrm{N}, 6.01^{\circ} \mathrm{E} ; 50 \mathrm{~m}\right.$ above MSL), located in the south-east of France. The measurement station is situated $\sim 8 \mathrm{~km}$ away from the urban city of Toulon in the west and $\sim 5 \mathrm{~km}$ from the Mediterranean coastline in the south. The district of Toulon consists of a total population of over half a million, with population density of $>400$ per square $\mathrm{km}$. The directly measured aerosol and radiometric quantities included scattering and absorption coefficients, number-size distributions of fine and coarse particles, columnar aerosol optical depth (AOD) and global broadband shortwave radiative fluxes at the surface.

The absorption coefficients $\left(\beta_{\mathrm{ab}}\right)$ were obtained using a multi-channel Aethalometer (Model AE-31, Magee Scientific), which also estimates the Black Carbon (BC) mass concentrations. Aethalometer measurements are mainly based on the aerosol light absorption. The mass of black carbon continuously accumulated on a quartz fibre tape is obtained by optical attenuation measurement and subsequent conversion using the calibration factor provided by the manufacturer (Hansen et al., 1984). The absorption coefficient was estimated at the seven wavelengths (viz. 370, 470, 520, 590, 660, 880 and $950 \mathrm{~nm}$ ) of the Aethalometer using the raw absorbance data following Weingartner et al. (2003). Scattering coefficient of aerosols $\left(\beta_{\mathrm{sc}}\right)$ is measured using a Nephelometer (Model M9004, Ecotech). Nephelometer draws the ambient air through an inlet tube, which is then illuminated by a flash lamp and the scattered light intensity is measured at $525 \mathrm{~nm}$ by a photo-multiplier tube. Temperature and pressure measurements made in the scattering chamber are used to calculate the scattering by air molecules, which are then subtracted from the total scattering to get the scattering due to aerosols. The instrument was calibrated regularly using standard procedure, in which the Nephelometer is adjusted to read zero by passing particle free air and the span calibration was done in the laboratory using $\mathrm{CO}_{2}$ gas. The scattering data were corrected for truncation errors following the work of Heintzenberg et al. (2006) for Ecotech Nephelometer. A Scanning Mobility Particle Sizer (SMPS Model 3936, TSI Inc.) with a differential mobility analyzer (Model 3080) and attached to a condensation particle counter (Model 3010), and optical particle counters (GRIMM 1.108 \& HIAC Royco 5250) were also being used for making measurements of nearsurface aerosol number concentration and size distribution covering the size range between 0.01 and $15 \mu \mathrm{m}$. The CIMEL sky radiometer was installed at the observation site under the AERONET/PHOTONS network (Holben et al., 1998). The CIMEL sky radiometer is an automatic tracking Sun and sky scanning radiometer with a field of view of $1.2^{\circ}$ and it measures the AOD at four different wavelengths (440, 675, 870 and $1020 \mathrm{~nm})$ and precipitable water vapor. A pyranometer (Model CM21, Kipp \& Zonen) has been used to obtain the broadband $(0.3-2.8 \mu \mathrm{m})$ global solar radiative fluxes at the surface. Finally, a meteorological station provided information on the air temperature, relative humidity, wind speed, wind direction, atmospheric pressure, and rain intensity. All the above instruments were part of the monitoring station proposed under the ACCENT program (Despiau et al., 2005). The measurement campaign was initiated from mid of October 2005, and continuous measurements were being made until the end of October 2006. The data collected during this period (spanning for 377 days) have been used in the present study.

\section{Results}

\subsection{Aerosol optical properties}

Fig. 1 shows the monthly-mean temporal variation of AOD at two representative wavelengths (440 and $1020 \mathrm{~nm}$ ), and precipitable water vapor content. AOD at $440 \mathrm{~nm}$ shows significant daily and monthly ( 0.1 and 0.34 ) variability, with quite high values $(>0.2)$ observed during the summer and autumn months, while low-to-moderate values prevailed during rest of the period. Highest monthly-mean AODs occurred during the warmest month of July and can be attributed to the prevailing high temperatures and anti-cyclonic circulation. On the other hand, low monthly-mean AODs in August were directly linked to the very high wind speeds conditions (shown in Fig. 2) associated with the mistral phenomena (Drobinski et al., 2005). Monthly variations of columnar water vapor showed similar variations to that of AOD, thereby indicating the impact of water

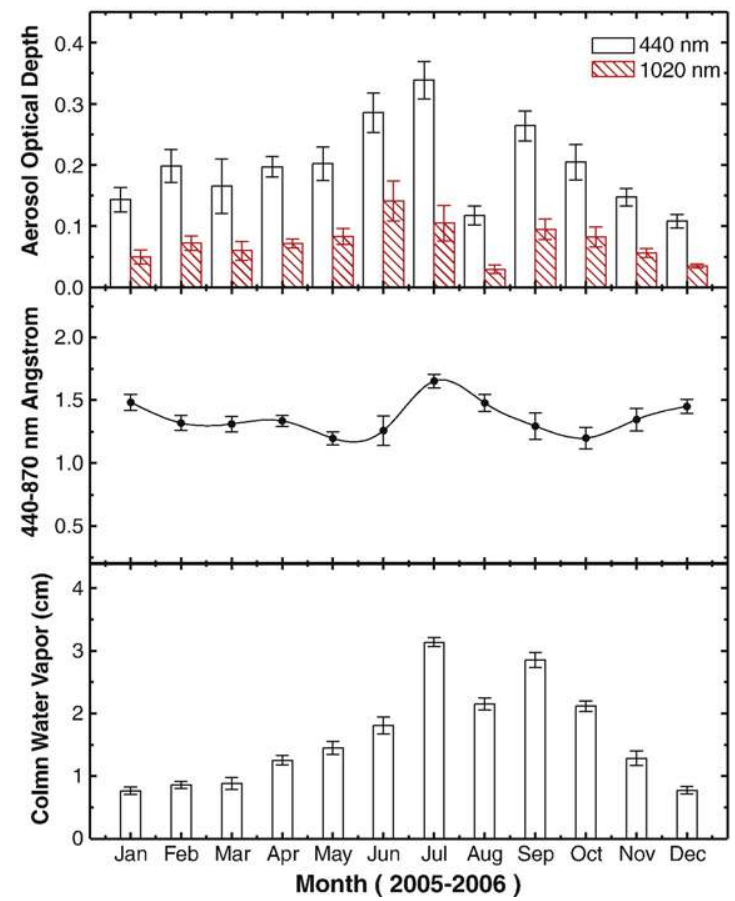

Fig. 1. Temporal variation of monthly-mean AOD at 440 and $1020 \mathrm{~nm}$ (top panel), Angstrom coefficient (middle panel), and columnar water vapor content (bottom panel). The error bars represent the standard error of the monthly ensembles. 


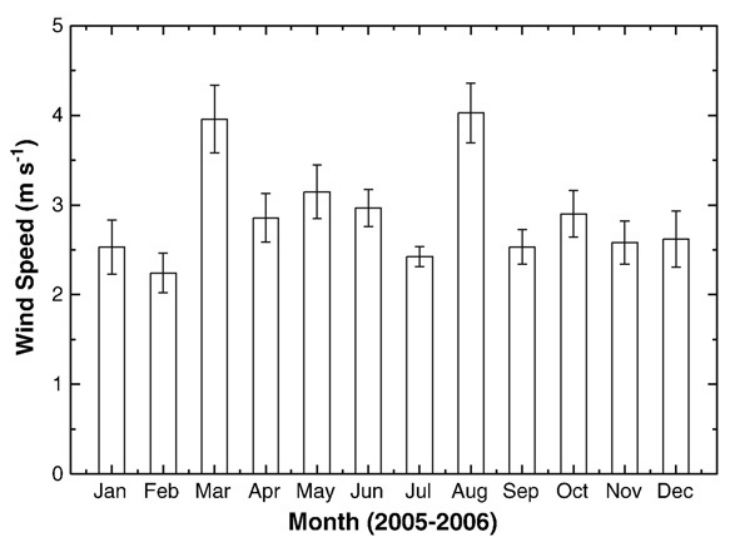

Fig. 2. Temporal variation of monthly-mean wind speed.

vapor on the aerosol optical properties. The Angstroms coefficient $(\alpha)$ estimated using the AODs at 440 to $870 \mathrm{~nm}$ wavelength range remained fairly high $(>1.2)$ during the entire study period (as shown in the middle panel of Fig. 1), thereby indicating the relative dominance of fine particles to the solar extinction. It is interesting to note that the moderately high AODs in June 2006 coincided with slightly reduced $\alpha$ with relatively large error bars as compared to the other months. This aspect when examined using the aerosol index maps onboard OMI (http://toms.gsfc.nasa.gov/aerosols/aerosols_v8.html) and back trajectories computed using HYSPLIT 4 (Draxler and Rolph,
2003) attributed the high aerosol loading days to the influence of African dust by long range transport. Figs. 3 and 4 shows the aerosol index map and 5-day back trajectory for 19th June (a representative day with very high aerosol loading and extremely low Angstrom coefficient), which very clearly demonstrates the strong influence of mineral dust transport from Africa at the measurement location.

Fig. 5 shows the monthly-mean temporal variation of nearsurface aerosol scattering and absorption coefficient respectively. High values of scattering and absorption coefficient are observed during the winter months (November through February) and low-to-moderate values prevailed during rest of the period (March through October). Higher values during winter months are attributed to the shallow boundary layer depths, lower wind speeds, and increase in the anthropogenic activity associated with space heating. Lowest monthly-mean values in August are again attributed to the very high wind speeds conditions associated with the mistral phenomena, which was frequently encountered during that month.

Although the patterns of seasonal variation of scattering and absorption coefficients evolve almost identically (as indicated in Fig. 5), small differences in the percentage variation of the individual parameters $\left(\beta_{\mathrm{ab}}\right.$ and $\left.\beta_{\mathrm{sc}}\right)$ from month to month would be reflected in the pattern of Single Scattering Albedo (SSA) which is the ratio of aerosol scattering to the total aerosol extinction coefficient. The seasonal averaged SSA at $525 \mathrm{~nm}$ was found to be $0.76 \pm 0.07,0.79 \pm 0.07,0.78 \pm 0.07$ and $0.73 \pm 0.08$ during winter (DJF), spring (MAM), summer (JJA) and autumn (SON) seasons, respectively. The low values

OMl Aerosol Index on June 19, 2006
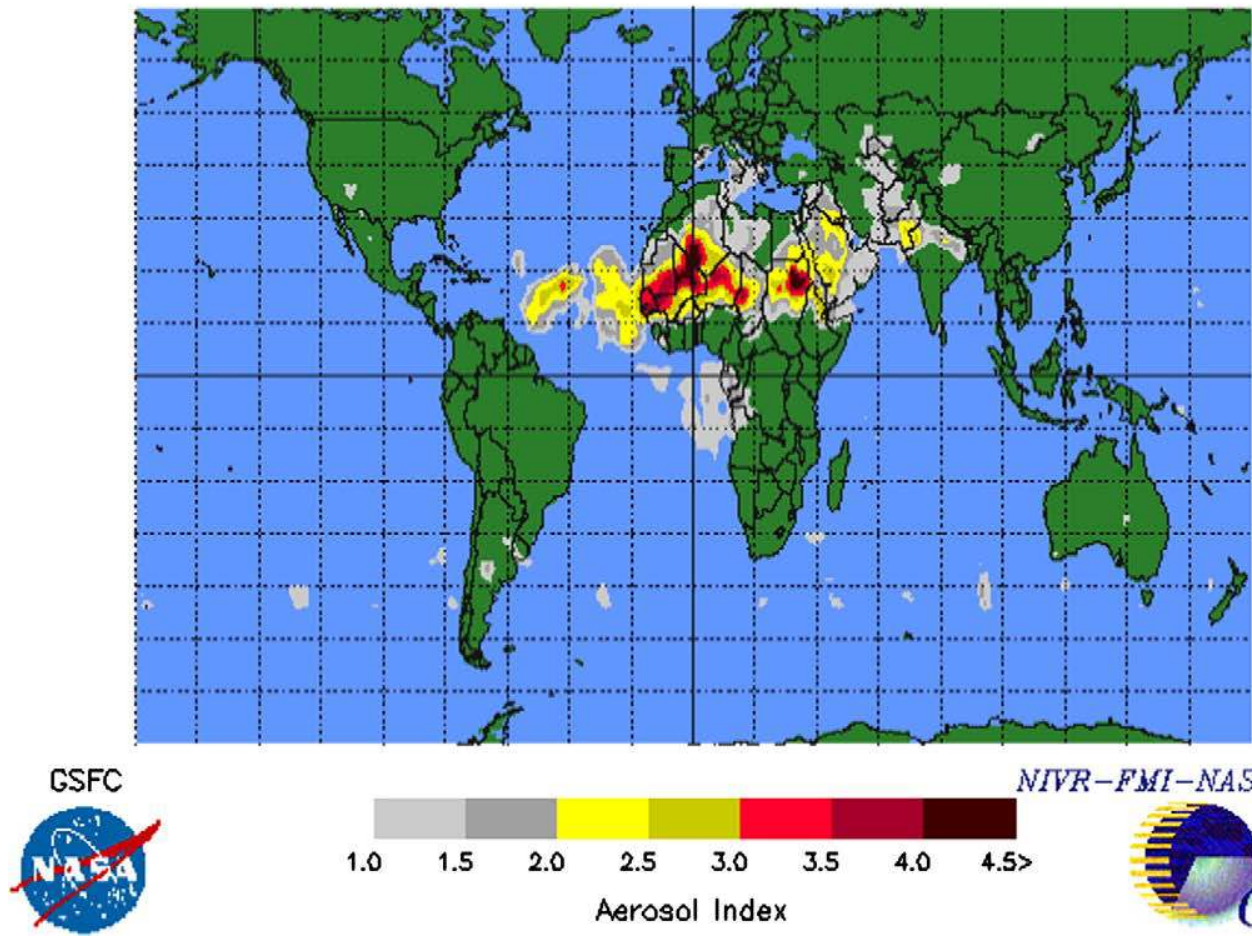

NIR $-F M I-N A S A-K N M I$

Fig. 3. Map of Aerosol Index for 19th June 2006. 
NOAA HYSPLIT MODEL

\section{Backward trajectories ending at 12 UTC 19 Jun 06 \\ FNL Meteorological Data}

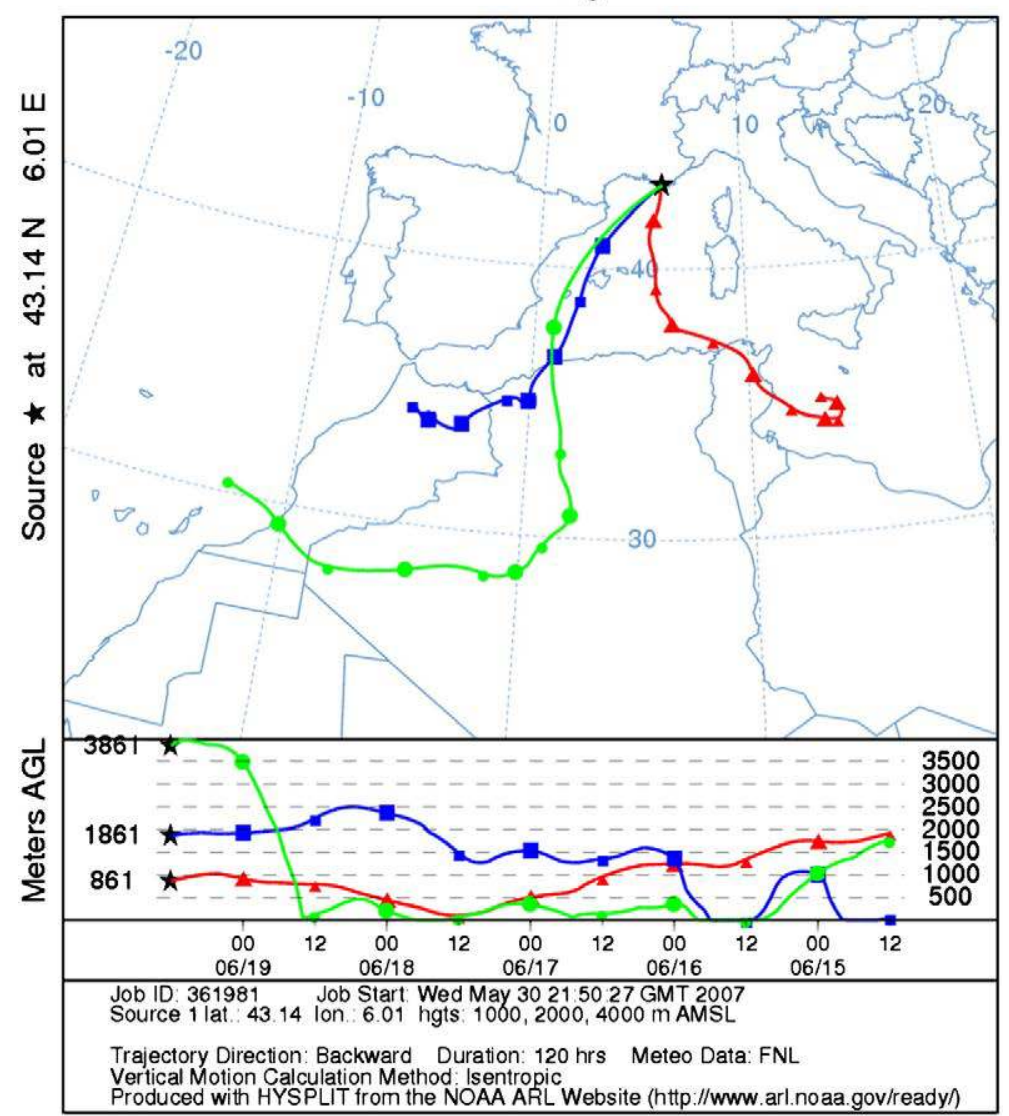

Fig. 4. 5-day back trajectories computed using HYSPLIT 4 for 19th June 2006. All the trajectories are terminating at the observation site at three altitude levels: $1000 \mathrm{~m}$ (lines joined by triangles), $2000 \mathrm{~m}$ (lines joined with squares) and $4000 \mathrm{~m}$ (lines joined by circles). The top panel shows the horizontal projection of the trajectories and the bottom shows the time-height profiles of the trajectories.

of SSA in autumn and winter months are attributed to the relative dominance of absorbing aerosols.

The values of SSA measured over Toulon are found to be consistent with those reported by Mallet et al. (2003) [0.83 \pm 0.04 ] over urban coastal Mediterranean region, Gerasopoulos et al. (2003) over Greece ( 0.78 to 0.80 at Ouranoupolis and 0.82 at Thessaloniki) and Di Iorio et al. (2003) at Lampedusa (0.79 to 0.83 for "aged" anthropogenic aerosols originating from Europe). The significantly low values of SSA obtained over Toulon indicate the dominance of absorbing aerosols over this region, which consequently will have implications on the regional radiative forcing.

\subsection{Direct aerosol radiative forcing}

\subsubsection{Radiative transfer modelling}

The clear-sky direct aerosol radiative forcing (DRF) has been computed using the radiative transfer code Global Atmospheric ModEl (GAME) (Dubuisson et al., 1996, 2004), which accounts for the scattering and absorption processes by particles and gases. In GAME, gaseous absorption $\left(\mathrm{H}_{2} \mathrm{O}, \mathrm{CO}_{2}\right.$, $\mathrm{O}_{2}$ and $\mathrm{O}_{3}$ ) is computed from the correlated $k$-distribution (Lacis and Oinas, 1991). Multiple scattering effects are treated using the Discrete Ordinates Method following the planeparallel approximation (Stamnes et al., 1988). Upward and Downward net radiative fluxes are calculated over the solar spectrum, ranging from 2500 to $50,000 \mathrm{~cm}^{-1}$, with a spectral resolution of $100 \mathrm{~cm}^{-1}$. More details on the methodology employed to estimate the diurnally averaged clear-sky radiative forcing and the associated heating rate due to particles are given in Roger et al. (2006) and Mallet et al. (2006).

In GAME, aerosol optical properties measured at the surface have been used as input for altitudes between 0 and $1 \mathrm{~km}$ for the polluted cases. This vertical profile is mainly based on aircraft measurements over this coastal region during the ESCOMPTE experiment (Mallet et al., 2003), which clearly showed that most anthropogenic aerosols are located below $1 \mathrm{~km}$ during summertime. In the case of mineral dust, since different vertical profiles have been observed over the Mediterranean basin (Balis et al., 2000; di Sarra et al., 2001), we have considered three cases with different vertical profiles for simulating the direct radiative forcing of dust aerosols (Table 1 ).

In order to estimate the aerosol asymmetry parameter $(g)$ at different wavelengths, calculations using Mie code have been performed from the aerosol number-size distribution 


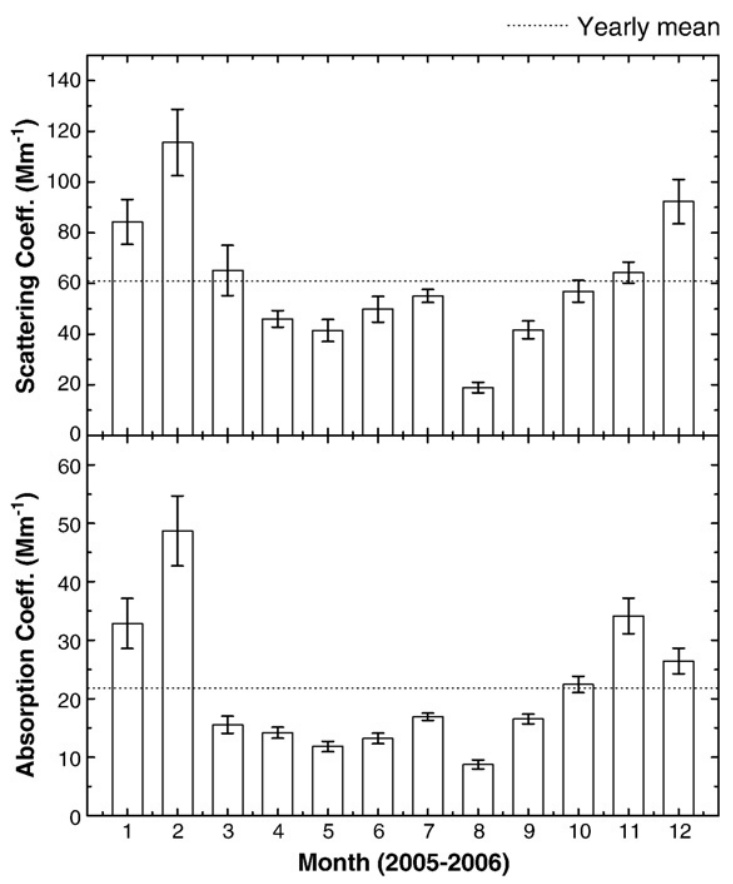

Fig. 5. Temporal variation of monthly-mean aerosol scattering coefficient (top panel) and absorption coefficient (bottom panel). Also shown in the figures are the yearly mean values as dotted lines.

(measured using SMPS) and the refractive index of aerosols in urban zone following Mallet et al. (2003). In case of dust aerosols, the refractive index values from d'Almeida et al. (1991) have been used in our computations. The values of $g$ reported in Table 1 are comprised between 0.62 and 0.68 for the polluted cases and 0.70 for the dust case.

Above the PBL (for the polluted cases), the aerosol optical properties obtained from aircraft measurements (Mallet et al., 2005) during the ESCOMPTE experiment have been used for altitudes between 1 and $3 \mathrm{~km}$. Authors indicate a mean aerosol single scattering albedo of 0.90 in the upper layer (1-3 km). For the free troposphere and stratosphere, the spectral variation of aerosol optical properties based on the aerosol models of Hess et al. (1998) has been used.

As no aircraft measurements or balloons soundings of $\mathrm{RH}$ were available over Toulon, we rely on the vertical profiles of $\mathrm{RH}$ obtained at Marseille during the ESCOMPTE experiment for the summer period. This is justified by the fact that similar surface RH values ( 40\%) were encountered over Toulon for the period investigated here and at Marseille during ESCOMPTE (Mallet et al., 2003). The MODIS albedo product providing the spectral dependence of surface albedo at seven wavelength bands has been used in our model simulations to reproduce the surface albedo.

A precise error budget has been performed by Roger et al. (2006) in the estimation of the direct radiative forcing from the GAME radiative transfer model. This not only takes into account of the uncertainties coming from chemical and physical parameters, which drive the optical properties, but also from the atmospheric profiles and surface albedo. Results for the polluted aerosols are summarized in Roger et al. (2006) and indicate an accuracy of $12-20 \%$ for the BOA forcing, and associated accuracies of $20 \%$ and $16 \%$, for the TOA and ATM forcings, respectively. These accuracies have been retained in our simulations for polluted aerosols. In parallel, independent computations of uncertainties have been performed for dust aerosols over Toulon, taking into account the possible vertical profiles of mineral dust.

\subsubsection{Direct radiative forcing for polluted and dust aerosols}

We performed the radiative simulations for four anthropogenic polluted events (07, 09, 11 and 22nd June 2006), and one dust event (19th June 2006) observed over Toulon. The polluted cases have been chosen with a large range of SSAs (Table 1). Subsequently (in Section 3.2.3), we have further extended our simulations for the entire summer period, when high AODs occur over Toulon (Fig. 1).

The results of the radiative transfer modelling are reported in Table 1. It should be noted that the downwards fluxes simulated by GAME match closely when compared with the surface observations (Fig. 6 ), with a mean difference of $\pm 5 \%$ for the cases studied here. As summarized in the Table 1, simulations indicate important daily radiative surface forcings for the days studied, with surface forcing $\left(\Delta F_{\mathrm{BOA}}\right)$ comprised between $-21 \pm 3.1$ and $-30 \pm 4.5 \mathrm{~W} \mathrm{~m}^{-2}$ for polluted cases (with a mean value of $-24 \pm 3.6 \mathrm{~W} \mathrm{~m}^{-2}$ ) and comprised between -61 and $-64 \mathrm{~W} \mathrm{~m}^{-2}$ for the dust event, depending of the vertical structure of extinction coefficients. The desert dust producing a larger surface forcing is associated with very high AOD ( 0.80 at $440 \mathrm{~nm}$ ). Our calculations are found to be consistent with the values reported in the literature for polluted aerosols in coastal regions. Radiative transfer simulations performed by Roger et al. (2006) during ESCOMPTE have showed a daily surface forcing of $-34 \mathrm{~W} \mathrm{~m}^{-2}$. The difference observed with our

Table 1

AOD (at $440 \mathrm{~nm}$ ), Angstroms coefficient $(\alpha)$, SSA and $g$ (at $525 \mathrm{~nm}$ ), daily direct radiative forcings $(\Delta F)$ in W $\mathrm{m}^{-2}$, forcing efficiencies in W $\mathrm{m}^{-2}$ AOD ${ }^{-1}$ and the mean heating rate (HER) in ${ }^{\circ} \mathrm{K}$ day $^{-1}$

\begin{tabular}{|c|c|c|c|c|c|c|c|c|c|c|c|c|}
\hline Date & Aerosol types & AOD & $\alpha$ & SSA & $g$ & $\Delta F_{\mathrm{BOA}}$ & $\Delta F_{\mathrm{TOA}}$ & $\Delta F_{\mathrm{ATM}}$ & $\mathrm{RE}_{\mathrm{BOA}}$ & $\mathrm{RE}_{\mathrm{TOA}}$ & $\mathrm{RE}_{\mathrm{ATM}}$ & HER \\
\hline 07 June & Continental polluted & 0.32 & 1.68 & 0.89 & 0.68 & -21.8 & -5.6 & 16.2 & -68.1 & -17.5 & 50.6 & 2.46 \\
\hline 09 June & Continental polluted & 0.22 & 1.81 & 0.76 & 0.64 & -21.5 & -2.3 & 19.2 & -97.6 & -10.6 & 87.1 & 3.16 \\
\hline 11 June & Continental polluted & 0.31 & 1.79 & 0.85 & 0.68 & -22.8 & -4.3 & 18.5 & -73.5 & -13.7 & 59.8 & 2.95 \\
\hline 22 June & Continental polluted & 0.34 & 1.30 & 0.80 & 0.62 & -29.8 & -5.7 & 24.1 & -87.7 & -16.6 & 71.0 & 4.61 \\
\hline 19 June & Continental dust $(0-4 \mathrm{~km})$ & 0.79 & 0.19 & 0.90 & 0.70 & -61.8 & -7.7 & 54.1 & -78.2 & -9.7 & 68.5 & $3.47^{*}$ \\
\hline 19 June & Continental dust $(0-2 \mathrm{~km})$ & 0.79 & 0.19 & 0.90 & 0.70 & -61.2 & -7.8 & 53.3 & -77.5 & -9.9 & 67.5 & \# \\
\hline 19 June & Continental dust ( $3-5 \mathrm{~km})$ & 0.79 & 0.19 & 0.90 & 0.70 & -64.4 & -9.8 & 54.6 & -81.5 & -12.4 & 69.1 & \# \\
\hline
\end{tabular}

HER is averaged within the PBL for the polluted cases, and for the dust event (19 June), the averaging has been done for three cases (0-4 km, $0-2 \mathrm{~km}$ and $3-5 \mathrm{~km})$. 


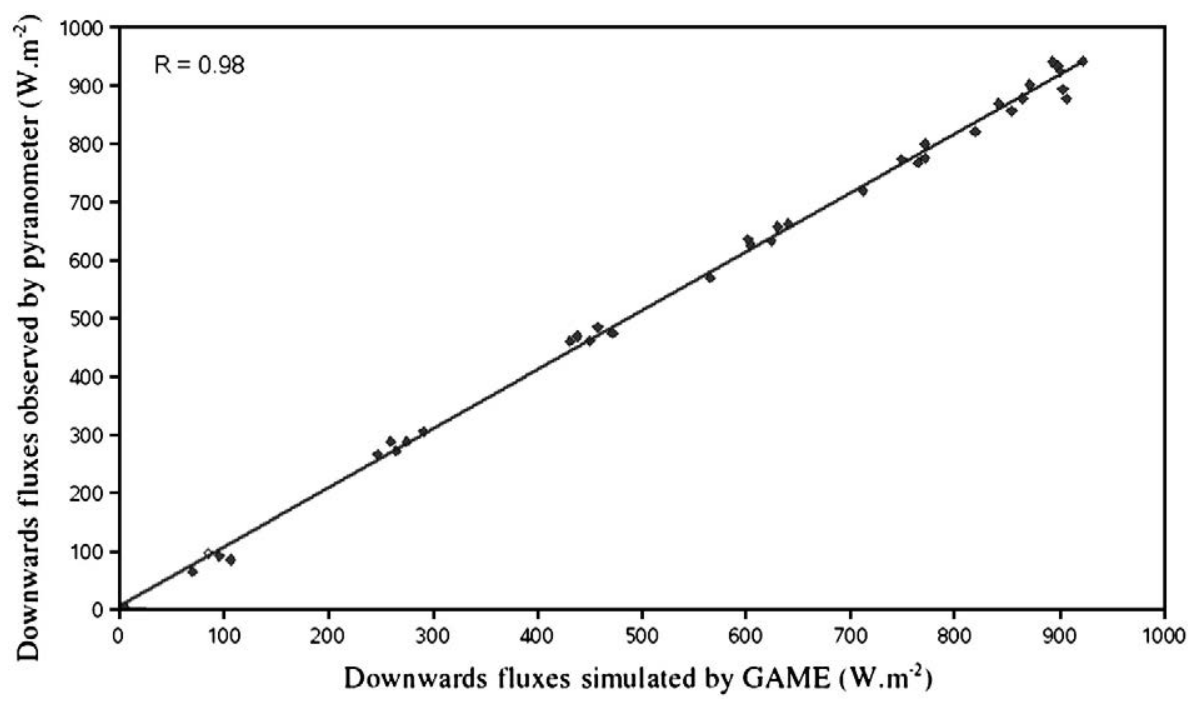

Fig. 6. Comparison between observed (Pyranometer) and model simulated (GAME) broadband fluxes at the surface.

simulations is due to larger AODs over Marseille/Fos-Berre region (Roger et al., 2006). Horvath et al. (2002) reported a daily surface forcing of $-23 \mathrm{~W} \mathrm{~m}^{-2}$ at Almeria (south Mediterranean coast of Spain), which is very close to the one estimated over Toulon, in spite of the relatively higher AOD at Almeria (0.40 at $550 \mathrm{~nm}$ ). The differences in this case can be attributed to the larger absorption over Toulon (mean SSA of 0.82) as compared to over Almeria. Concerning dust aerosols, the surface forcing obtained over Toulon is higher than the one reported by Meloni et al. (2003) at Lampedusa $\left(-36.7 \mathrm{~W} \mathrm{~m}^{-2}\right)$ during the dust event of May 18,1999 . This difference is mainly due to the lower value of the AOD observed at Lampedusa ( 0.51 at $415 \mathrm{~nm}$ ) compared to the one observed at Toulon ( 0.80 at $440 \mathrm{~nm})$.
The DRFs at the top of the atmosphere $\left(\Delta F_{\mathrm{TOA}}\right)$ are found to be very low compared to the surface forcings (Table 1 ). This is consistent with the very low SSA prevailing over Toulon, which causes a strong absorption of solar radiation by aerosols at the surface. In case of pure scattering particles (such as sulphate or sea salt), the majority of flux loss at the surface is reflected back to space, and hence $\Delta F_{\mathrm{TOA}}$ would be similar to $\Delta F_{\mathrm{BOA}}$. This equivalence is not valid in case of absorbing aerosols (for SSA's much lower than 1 ). Over Toulon, $\Delta F_{\mathrm{TOA}}$ is comprised between $-2.3 \pm 0.5$ and $-5.7 \pm 1.1 \mathrm{~W} \mathrm{~m}^{-2}$ for polluted aerosols and comprised between -7.7 and $-10 \mathrm{~W} \mathrm{~m}^{-2}$ for the dust case (see Table 1). Our simulations are found to be consistent with TOA forcings reported for coastal polluted

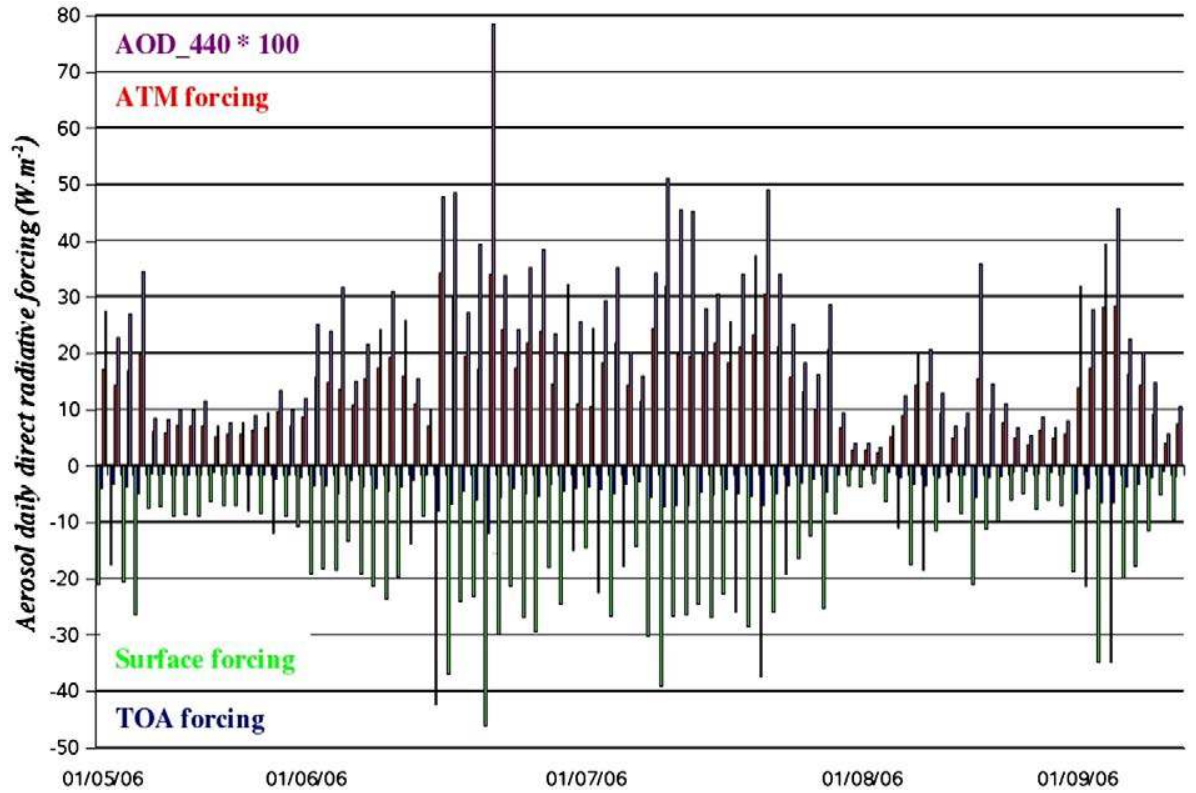

Fig. 7. Clear-sky direct aerosol radiative forcing (at BOA, TOA and ATM) and AOD (at $440 \mathrm{~nm}$ ) for the period May-September 2006. 
aerosols by Roger et al. (2006) during ESCOMPTE $(-7.7 \pm 1.5 \mathrm{~W}$ $\mathrm{m}^{-2}$ ) and by Horvath et al. (2002) during June 1999 at Almeria, with $-4.2 \mathrm{~W} \mathrm{~m}^{-2}$ (AOD of 0.40 at $550 \mathrm{~nm}$ ). The dust event observed over Toulon produces logically larger TOA forcing $\left(-7.7\right.$ to $\left.-10 \mathrm{~W} \mathrm{~m}^{-2}\right)$ than the one reported by Meloni et al. (2003) on Lampedusa with $-1.6 \mathrm{~W} \mathrm{~m}^{-2}$ (AOD of 0.51 at $415 \mathrm{~nm}$ ), due to the high AOD ( 0.80 at $440 \mathrm{~nm}$ ).

Our results clearly indicate that large amount of solar radiation is capped by aerosols over Toulon. This is well underlined by the important values of the daily atmospheric forcing $\left(\Delta F_{\mathrm{ATM}}\right)$ calculated for each case (polluted and dust events). As reported in the Table $1, \Delta F_{\mathrm{ATM}}$ is comprised between $16 \pm 2.6 \mathrm{~W} \mathrm{~m}^{-2}$ for polluted aerosols, and 53 to $54 \mathrm{~W} \mathrm{~m}^{-2}$ for dust particles. The larger value is expectedly obtained for the dust event, when large AODs occur. However, if we compute the Radiative Efficiency, RE (defined as the radiative forcing per unit of AOD), we can see that the higher value of the atmospheric $\mathrm{RE}$ is obtained for the 09 June $\left(+97.6 \mathrm{~W} \mathrm{~m}^{-2} \mathrm{AOD}^{-1}\right)$, which corresponds to the lower SSA (0.76). The atmospheric forcing leads to a significant increase in the heating rate (HER) of the atmosphere, which has been computed following Roger et al. (2006). For polluted cases, HER is comprised between 2.46 and $4.61 \mathrm{~K} \mathrm{day}^{-1}$ and is strongly correlated with SSA and AOD. The larger value is obtained for 22nd June, which is characterized by high AOD and low SSA (0.80). These values are consistent with those reported by Roger et al. (2006), with HER of $2.8 \mathrm{~K} \mathrm{day}^{-1}$ for the most polluted case of the ESCOMPTE experiment.

\subsubsection{Implications for the May-September 2006 period}

We extended our radiative simulations for the entire summer time (May through September), which corresponded to the most polluted period (with high AODs) over the coastal region of Toulon (Fig. 1). In order to obtain the day-to-day clear-sky aerosol forcing at the surface and at the TOA, we have used the average of the RE values obtained for polluted particles (Table 1) and adjusted it with reference to the SSA and AOD values obtained for each day (see Section 3.2.1). The direct radiative forcing obtained from this methodology, associated with the corresponding AOD is shown in Fig. 7. We observed a strong variability in the radiative effect during the summer period, which is strongly correlated with the aerosol loading (Fig. 1), with higher values of monthly-mean surface forcing in July $\left(-23 \pm 3.4 \mathrm{~W} \mathrm{~m}^{-2}\right)$ and lower values in August $\left(-9 \pm 1.3 \mathrm{~W} \mathrm{~m}^{-2}\right)$.

It is interesting to note that significant aerosol forcings are observed for long duration. From Fig. 7, our results clearly indicate the presence of an important pollution event, occurring from the mid of June to the end of July, which is quite remarkable for its duration and characterized by significantly high AODs ( 0.2 to 0.5 at $440 \mathrm{~nm}$ ). During this period, significant aerosol forcings are simulated. The surface forcing is comprised between $-16 \pm 2.4$ and $-48 \pm 7.2 \mathrm{~W} \mathrm{~m}^{-2}$ (mean of $-26 \pm 3.9 \mathrm{~W} \mathrm{~m}^{-2}$ ), the TOA between $-2.6 \pm 0.5$ and $-12 \pm 2.4 \mathrm{~W} \mathrm{~m}^{-2}$ (mean of $-5.2 \pm 0.8 \mathrm{~W} \mathrm{~m}^{-2}$ ) and the atmospheric forcing between $13 \pm 2.1 \mathrm{~W} \mathrm{~m}^{-2}$ and $35 \pm 5.6 \mathrm{~W} \mathrm{~m}^{-2}$ (mean of $20.5 \pm 3.3 \mathrm{~W} \mathrm{~m}^{-2}$ ) during the study period. These results indicate that polluted aerosols over coastal region can heat the lower atmosphere by $\sim 2 \mathrm{Kday}^{-1}$ or even more during the long time period. These results are in good agreement with those obtained by Pace et al. (2005) that estimated the fire aerosol radiative forcing to be 21.6 and $25.7 \mathrm{~W} \mathrm{~m}^{-2}$ over the Mediterranean basin during summer 2003, causing an increase in the heating rates up to $2.8 \mathrm{~K} \mathrm{day}^{-1}$, consistent with the one simulated over Toulon $\left(2.0 \mathrm{~K} \mathrm{day}^{-1}\right)$. As mentioned by Pace et al. (2005), polluted aerosols over the coastal Mediterranean region could also reinforce the atmospheric stability contributing to maintain the "heat waves" conditions during summer time over this region. Future modelling studies are required for investigating the role of polluted aerosols observed over this region on the meteorological conditions (impact on the atmospheric stability and maintenance of the summer heat-wave).

Furthermore, as reported by Jacobson (1998), Li et al. (2005) and Hodzic et al. (2007), the presence of polluted aerosols could significantly modify the photolysis frequencies $\mathrm{J}\left[\mathrm{NO}_{2}\right]$ and $\mathrm{J}\left[\mathrm{O}_{3}\left({ }^{1} \mathrm{D}\right)\right]$. Li et al. (2005)] reported a reduction of photolysis frequencies $\mathrm{J}\left[\mathrm{NO}_{2}\right]$ and $\mathrm{J}\left[\mathrm{O}_{3}\left({ }^{1} \mathrm{D}\right)\right]$ by black carbon particles to $10-30 \%$ under highly polluted conditions in Houston area, leading to a modelled decrease of surface ozone concentrations by $5-20 \%$. Future works are also clearly required to quantify the possible effect of polluted particles on photolysis rates over this region, as they seem to have an important impact on local air quality.

\section{Conclusions}

Simultaneous measurements of aerosol physical and optical properties and radiative fluxes were analyzed to study the effect of aerosols on shortwave radiation at a Mediterranean coast in south France. The major conclusions of our study are:

1. Monthly-mean AOD at $440 \mathrm{~nm}$ ranged between $\sim 0.1$ and 0.34 . High Angstrom coefficients ( $>1.2)$ prevailed during the entire study period, thereby indicating the relative dominance of sub-micron aerosols.

2. The single scattering albedo at $525 \mathrm{~nm}$ ranged between 0.7 and 0.8 , indicating significant absorption.

3. Diurnal averaged clear-sky direct aerosol radiative forcing during summer over Toulon was in the range $-16 \pm 2.4$ to $-48 \pm 7.2 \mathrm{~W} \mathrm{~m}^{-2}$ at the surface and $-2.6 \pm 0.5$ to $-12 \pm 2.4 \mathrm{~W}$ $\mathrm{m}^{-2}$ at the top of the atmosphere, thereby leading to an atmospheric absorption of $13 \pm 2.1$ to $35 \pm 5.6 \mathrm{~W} \mathrm{~m}^{-2}$.

4. The shortwave atmospheric absorption translates to an atmospheric heating of 2.5 to $4.6 \mathrm{~K} \mathrm{day}^{-1}$ within the planetary boundary layer.

5. In addition to aerosol radiative forcings, future studies should investigate the impact of particulate pollution on atmospheric stability and maintenance of the summer heat-wave frequently occurring over this region.

\section{Acknowledgments}

The present work is supported by French CNRS, INSU, and PNTS Projects. One of the authors (AS) would like to acknowledge the French Ministry for Education \& Research and the Université du Sud Toulon-Var for providing the financial support. The authors would also like to acknowledge the NOAA Air Resources Laboratory (ARL) for the provision of HYSPLIT transport and dispersion model and READY website (http://www.arl.noaa.gov/ready.html) and TOMS/OMI for aerosol index map used in this publication. 


\section{References}

Balis, D., Papayannis, A., Galani, E., Marenco, F., Santacesaria, V., Hamonou, E., Chazette, P., Ziomas, I., Zerefos, C., 2000. Tropospheric LIDAR aerosol measurements and sun photometric observations at Thessaloniki Greece. Atmospheric Environment 34, 925-932.

Cros, B., Durand, P., Cachier, H., Drobinski, Ph., Fréjafon, E., Kottmeier, C., Perros, P., Peuch, V., Ponche, J.-L., Robin, D., Said, F., Toupance, G. Wotham, H., 2004. The ESCOMPTE Program: an overview. Atmospheric Research 69, 241-279.

d'Almeida, G.A., Koepke, P., Shettle, E.P., 1991. Atmospheric Aerosols: Global Climatology and Radiative Characteristics. A. Deepak Publishing, Hampton, Virginia.

Despiau, S., Piazzola, J., Missamou, T., 2005. A French Mediterranean site for atmospheric studies and surveillance. First ACCENT Symposium, Urbino (Italy).

Di Iorio, T. di Sarra, A., Junkermann, W., Cacciani, M., Fiocco, G., Fua, D., 2003. Tropospheric aerosols in the Mediterranean: 1 . Microphysical and optical properties. Journal of Geophysical Research 108, 4316. doi:10.1029/ 2002JD002815.

di Sarra, A., Di Iorio, T., Cacciani, M., Fiocco, G., Fua, D., 2001. Saharan dust profiles measured by lidar at Lampedusa. Journal of Geophysical Research 106, 10335-10347.

Draxler, R.R., Rolph, G.D., 2003. HYSPLIT (Hybrid Single-Particle Lagrangian Integrated Trajectory) software. NOAA Air Resource Laboratory, Silver Spring, Md. (Available at http://www.arl.noaa.gov/ready/hysplit4.html).

Drobinski, P., Bastin, S., Guenard, V., Caccia, J.-L., Dabas, A.M., Delville, P., Protat, A., Reitebuch, O., Werner, C., 2005. Summer mistral at the exit of the Rhone valley. Quarterly Journal of the Royal Meteorological Society 131, 353-375.

Dubuisson, P., Buriez, J.C., Fouquart, Y., 1996. High spectral resolution solar radiative transfer in absorbing and scattering media: application to the satellite simulation. Journal of Quantitative Spectroscopy \& Radiative Transfer 55, 103-126.

Dubuisson, P., Dessailly, D., Vesperini, M., Frouin, R., 2004. Water vapor retrieval over ocean using near-infrared radiometry. Journal of Geophysical Research 109, D19106. doi:10.1029/2004JD004516.

Gerasopoulos, E., Andreae, M.O., Zerefos, C.S., Andreae, T.W., Balis, D., Formenti, P., Merlet, P., Amiridis, V., Papastefanou, C., 2003. Climatological aspects of aerosol optical properties in Northern Greece. Atmospheric Chemistry and Physics 3, 2025-2041.

Hansen, A.D.A., Rosen, H., Novakov, T., 1984. The aethalometer - an instrument for the real-time measurement of optical absorption by aerosol particles. Science of the Total Environment 36, 191-196.

Heintzenberg, J., et al., 2006. Intercomparisons and aerosol calibrations of 12 commercial integrating nephelometers of three manufacturers. Journal of Atmospheric and Oceanic Technology 23, 902-914.

Hess, M., Koepke, P., Schult, I., 1998. Optical properties of aerosols and clouds: the software package. Bulletin of American Meteorological Society 79 , 831-844.

Hodzic, A., Madronich, S., Bohn, B., Massie, S., Menut, L., Wiedinmyer, C., 2007 Wildfire particulate matter in Europe during summer 2003: measo-scale modeling of smoke emissions, transport and radiative effects. Atmospheric Chemistry and Physics 7, 4043-4064.
Holben, B.N., Eck, T.F., Slutsker, I., Tanre, D., Buis, J.P., Setzer, A., Vermote, E., Reagan, J.A., Kaufman, Y.J., Nakajima, T., Lavenu, F., Jankowiak, I., Smirnov, A., 1998. AERONET - a federated instrument network and data archive for aerosol characterization. Remote Sensing of Environment 66, 1-16.

Horvath, H., Alados Arboledas, L., Olmo, F.J., Jovanovic, O., Gangl, M., Kaller, W., Sanchez, C., Sauerzopf, H., Seidl, S., 2002. Optical characteristics of the aerosol in Spain and Austria and its effect on radiative forcing. Journal of Geophysical Research 107, 4386. doi:10.1029/2001JD001472.

Jacobson, M.Z., 1998. Studying the effects of aerosols on vertical photolysis rate coefficient and temperature profiles over an urban airshed. Journal of Geophysical Research 103, 10593-10604.

Lacis, A.A., Oinas, V., 1991. A description of the correlated k-distribution method. Journal of Geophysical Research 96, 9027-9064.

Lelieveld, J., et al., 2002. Global air pollution crossroads over the Mediterranean. Science 298, 794-798.

Li, G., Zhang, R., Fan, J., Tie, X., 2005. Impact of black carbon aerosol on photolysis and ozone. Journal of Geophysical Research 110, D23206. doi:10.1029/2005JD005898.

Mallet, M., Roger, J.C., Despiau, S., Dubovik, O., Putaud, J.P., 2003. Microphysical and optical properties of aerosol particles in urban zone during ESCOMPTE. Atmospheric Research 69, 73-97.

Mallet, M., Dingenen, R.V., Roger, J.C., Despiau, S., Cachier, H., 2005. In situ airborne measurements of aerosol optical properties during photochemical pollution events. Journal of Geophysical Research 110, D03205. doi:10.1029/2004JD005139.

Mallet, M., Pont, V., Liousse, C., Roger, J.C., Dubuisson, P., 2006. Simulation of aerosol radiative properties with the ORISAM-RAD model during a pollution event (ESCOMPTE 2001). Atmospheric Environment 40, 7696-7705.

Meloni, D., di Sarra, A., DeLuisi, J., Di Iorio, T., Fiocco, G., Junkermann, W., Pace, G., 2003. Tropospheric aerosols in the Mediterranean: 2. Radiative effects through model simulations and measurements. Journal of Geophysical Research 108 (D10), 4317. doi:10.1029/2002JD002807.

Pace, G., Meloni, D., di Sarra, A., 2005. Forest fire aerosol over the Mediterranean basin during summer 2003. Journal of Geophysical Research 110, D21202. doi:10.1029/2005JD005986.

Roger, J.C., Mallet, M., Dubuisson, P., Cachier, H., Vermote, E., Dubovik, O., Despiau, S., 2006. A synergetic approach for estimating the local direct aerosol forcing: application to an urban zone during the Expérience sur Site pour Contraindre les Modèles de Pollution et de Transport d'Emission (ESCOMPTE) experiment. Journal of Geophysical Research 111, D13208. doi:10.1029/2005JD006361.

Stamnes, K., Tsay, S., Wiscombe, W., Jayaweera, K., 1988. Numerically stable algorithm for discrete-ordinate-method radiative transfer in multiple scattering and emitting layered media. Applied Optics 27, 2502-2509.

Weingartner, E., Saathoff, H., Schnaiter, M., Streit, N., Bitnar, B., Baltensperger, U., 2003. Absorption of light by soot particles: determination of the absorption coefficient by means of aethalometers. Journal of Aerosol Science 34, 1445-1463. 